\title{
AVALIAÇÃO DO MODELO BRAMS NA FORMAÇÃO DE NEVOEIRO DE RADIAÇÃO EM AMBIENTE COM TURBULÊNCIA POUCO DESENVOLVIDA.
}

\author{
EVERSON DAL PIVA e VAGNER ANABOR \\ Centro Regional Sul do Instituto Nacional de Pesquisas Espaciais - CRS/INPE \\ Santa Maria - RS \\ everson.bento@gmail.com, \\ vanabor@hotmail.com
}

Recebido Janeiro 2008 - Aceito Julho 2008

\begin{abstract}
RESUMO
Nevoeiro de radiação é normalmente precedido por forte resfriamento noturno. Em determinados eventos, a magnitude deste resfriamento é tão intensa que os modelos operacionais de previsão de tempo não conseguem representa-lo adequadamente. Simulações foram realizadas com o objetivo de reproduzir a formação do nevoeiro de radiação, observado na madrugada do dia 18 de abril de 2007. Foram testados parâmetros e parametrizações relacionados a turbulência disponíveis no modelo BRAMS versão 3.2. Para o cálculo do coeficiente de difusão vertical foram testados os esquemas de Mellor-Yamada e Smagorinsky, e para a razão entre os coeficientes de difusão vertical para escalares e para o momentum foram testados os valores 1 e 3. Os melhores resultados foram obtidos com o esquema de Mellor-Yamada e a razão 1 entre os coeficientes. A máxima taxa de resfriamento foi de $-5,7^{\circ} \mathrm{C} / 10 \mathrm{~h}$ e a taxa de umedecimento foi de $27,1 \% / 10 \mathrm{~h}$, mas os dados observados indicaram valores de $-8,8^{\circ} \mathrm{C} / 10 \mathrm{~h}$ e $29 \% / 10 \mathrm{~h}$, respectivamente. Com relação aos erros e taxas de resfriamento e umedecimento em superfície, as opções testadas geraram apenas pequenas melhoras nos resultados, mas foram suficientes para desenvolver o nevoeiro em superfície.

Palavras-Chave: Nevoeiro, modelo regional, previsão de tempo.
\end{abstract}

ABSTRACT: BRAMS MODEL EVALUATION WITH RELATION TO FORMATION OF THE RADIATION FOG IN THE ENVIRONMENT WITH NOT WELL-DEVELOPED TURBULENCE The radiation fog usually is preceded by a strong nocturnal cooling rate. Some times the observed cooling is so high that weather forecast models are not able to reproduce it accurately. Simulations were used to reproduce the formation of radiation fog at dawn on 18 April, 2007. Parameters and parameterizations related to turbulence available in BRAMS version 3.2 were tested. To calculate the vertical diffusion coefficients the Mellor-Yamada and Smagorinsky schemes were tested; and for the ratio of vertical diffusion coefficients between scalars and momentum the values 1 and 3 were tested. The best results were provided by the Mellor-Yamada parameterization scheme and when the ratio of vertical diffusion coefficients equal to 1 . The maximum cooling rate obtained was $-5,7^{\circ} \mathrm{C} / 10 \mathrm{~h}$ and the moistening rate was $-27,1 \% / 10 \mathrm{~h}$, but the observed data showed values of $-8,8^{\circ} \mathrm{C} / 10 \mathrm{~h}$ and $29 \% / 10 \mathrm{~h}$, respectively. In terms of surface cooling and moistening rate errors, the tested schemes led to small improvements in the results, but were sufficient to develop the fog over the surface.

Keywords: fog, regional model, weather forecasting. 


\section{INTRODUÇÃO}

Nevoeiro é um fenômeno atmosférico que ocorre na Camada Limite Planetária (CLP), caracterizando-se por reduzir a visibilidade horizontal para menos do que $1 \mathrm{~km}$ de distância. A redução da visibilidade ocorre devido a condensação do vapor de água próximo a superfície, e afeta principalmente os setores de transporte e agrícola. Devido aos prejuízos causados pelos nevoeiros, Lima (1982) desenvolveu uma metodologia para a previsão de nevoeiro de radiação para Porto Alegre e determinou que para ele ocorrer, é necessário que as $19 \mathrm{~h}$ a direção do vento seja de leste ou sudeste e tenham intensidade abaixo de $1,4 \mathrm{~m} / \mathrm{s}$.; e o déficit da temperatura do ponto de orvalho seja menor do que $1^{\circ} \mathrm{C}$.

Apesar de ser um fenômeno que ocorre na CLP, a formação do nevoeiro depende da situação sinótica predominante na região, sendo assim é um bom exemplo da interação entre escala sinótica e a microescala.

Para Porto Alegre, Piva e Fedorova (1999) estudaram 11 casos de nevoeiro de radiação ocorridos no ano de 1995. Seus resultados mostraram que 8 deles $(72,7 \%)$ ocorreram no outono, e que um anticiclone transiente encontrava-se sobre o nordeste ou a leste do Estado do Rio Grande do Sul no dia anterior e no dia com nevoeiro.

Para Santa Maria (no centro do Estado do Rio Grande do Sul) não há um estudo estatístico sobre a ocorrência de nevoeiro de radiação, mas observações in situ do próprio autor, indicam que a cidade apresenta um alto índice de ocorrência deste fenômeno. Por exemplo, entre os meses de junho e setembro de 2006 foram observadas 15 ocorrências de nevoeiros, e entre os 5 primeiros meses de 2007 foram registradas 12 ocorrências.
Destaca-se o mês de julho de 2006, no qual foram registrados nevoeiros em 5 manhãs seguidas entre os dias 2 e 6 . Devido a ausência de grandes lâminas de água e pelas características atmosféricas observadas nas situações de nevoeiros em Santa Maria, pode-se afirmar que tratam-se de nevoeiros de radiação, cujo o principal processo de formação é a perda radiativa durante o período noturno. Isso não impede que ventos fracos, soprando de regiões alagadas em direção a Santa Maria, possam auxiliar na formação do nevoeiro. Deve-se levar em conta este escoamento pois em situações com nevoeiro, geralmente a direção do vento ao longo da Depressão Central do Estado do Rio Grande do Sul adquire direção de leste (J. L. Fontinele, 2007, comunicação pessoal). Neste caso, talvez se assemelhe mais a um nevoeiro formado devido à radiação-advecção. Estas situações são caracterizadas por calmaria ou ventos com magnitude em torno de 1 a $3 \mathrm{~m} / \mathrm{s}$, e conseqüentemente fraca turbulência. Turbulência pouco desenvolvida torna-se problema para a modelagem atmosférica, pois as parametrizações turbulentas são desenhadas para situações de CLP convectiva, ou seja, com turbulência bem desenvolvida.

O processo de resfriamento noturno, responsável pela formação do nevoeiro de radiação, não é adequadamente representado pelos modelos atmosféricos utilizados na previsão de tempo operacional como indica a Figura 1. Nesta figura são mostradas previsões de 3 dias para 3 modelos (BRAMS, WRF e ETA; vide legenda), com diferentes configurações e diferentes dados de condição inicial e de contorno. Pode-se observar, que os modelos tem dificuldade em representar situações de forte resfriamento noturno como indicado nas observações METAR (quadrados na figura 1).

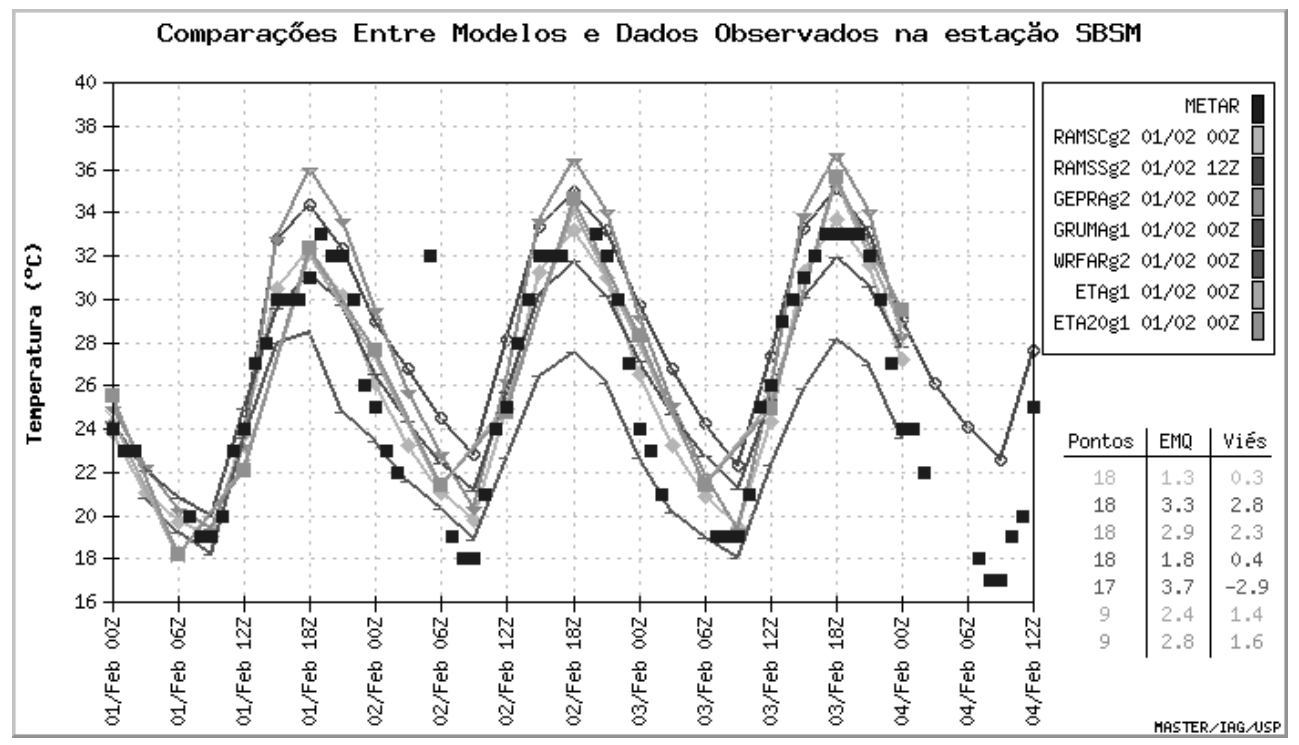

Figura 1 - Previsões operacionais (linhas contínuas) de temperatura em superfície $\left({ }^{\circ} \mathrm{C}\right)$ para 3 modelos atmosféricos (vide legenda) e observações do METAR (quadrados) para a estação SBSM (aeroporto de Santa Maria). Período mostrado: 01-04 de fevereiro de 2007.

Fonte: Adaptada de MASTER/USP. 
O Grupo de Modelagem Atmosférica (GRUMA) da Universidade Federal de Santa Maria (UFSM) mantêm, desde maio de 2006, um sistema de previsão de tempo operacional baseado no modelo BRAMS (Brazilian Regional Atmospheric Modeling System). Entretanto, sua capacidade para simular fortes taxas de resfriamento noturno e por consequência a sua capacidade em prever a formação de nevoeiro de radiação ainda não foi avaliada.

Este trabalho tem por objetivo testar as opções de parametrizações e parâmetros relacionados a turbulência disponíveis na versão 3.2 do BRAMS, para um caso de nevoeiro de radiação, que se caracteriza por fraca turbulência atmosférica, ocorrido na madrugada do dia 18/04/2007.

\section{DADOS E METODOLOGIA}

Neste estudo foram usados os seguintes conjuntos de dados: i) análise e previsão do Modelo de Circulação Geral (MCG, T126L28) do Centro de Previsão do Tempo e Estudos Climáticos do Instituto Nacional de Pesquisas Espaciais (CPTEC/INPE); ii) imagens de satélite GOES 10, produto nevoeiro-stratus da Divisão de Satélites Ambientais (DSACPTEC/INPE) e GOES 12 canal infravermelho da NASAGSFC; iii) dados de umidade do solo (Gevaerd e Freitas, 2006) disponibilizado pelo grupo Meteorologia Aplicada a Sistemas de Tempo Regionais (MASTER-IAG/USP); iv) mensagem METAR da estação SBSM da Aeronáutica; v) carta de pressão da Diretoria de Hidrografia e Navegação (DHN) da
Marinha; vi) carta SYNOP do CPTEC/INPE; vii) observações horárias da estação automática (A803) do Instituto Nacional de Meteorologia (INMET) localizada em Santa Maria; e viii) previsão operacional do GRUMA/UFSM e simulações com o modelo BRAMS.

As simulações foram realizadas com o BRAMS versão 3.2, o qual é a versão 5.04 do RAMS (Regional Atmospheric Modeling System) com ênfase nos trópicos (Fazenda et al., 2006), e inclui atualizações e novas parametrizações, podendo-se destacar o uso da umidade do solo heterogênea e a parametrização de cumulus rasos e profundos. Suas características são (Cotton et al., 2003; Panetta et al., 2002): grade tipo C de Arakawa; coordenada vertical shaved "ETA"; convecção profunda parametrizada pelo esquema de Grell, com fechamento conjunto (ensemble), onde o fluxo de massa é dado pela média de 5 fechamentos, são eles: Grell padrão, omega na base da nuvem, convergência de umidade na coluna, tipo Fritsch-Chappel ou Kain-Fritsch e Arakawa-Schubert; parametrização de convecção cumulus rasos ativada; relaxação (nudging) aplicada em todo o domínio, sendo mais forte nos 5 pontos mais externos e diminuindo para um mínimo no centro do domínio; parametrização da radiação de onda longa e curta segue o esquema de Chen e Cotton (1983); esquema de topografia média derivada de mapas com resolução de $10 \mathrm{~km}$ e $1 \mathrm{~km}$; modelo LEAF-3 (Walko et al., 2000) ativo sobre o solo; microfísica de nuvens parametrizada pelo esquema proposto por Walko et al. (1995), leva em consideração 7 tipos de hidrometeoros, sendo 2 líquidos (nuvem e chuva), 3 sólidos (pristine, neve e agregado)

Tabela 1 - Simulações realizadas. K indica o esquema usado para cálculo do coeficiente de difusão vertical (K=1 esquema de Mellor-Yamada e $\mathrm{K}=2$ esquema de Smagorinsky) e R indica a razão entre os coeficientes de difusão vertical para escalares e para o momentum.

\begin{tabular}{|c|c|c|c|}
\hline Simulação & $\mathrm{K}$ & $\mathrm{R}$ & Observação \\
\hline E_OP & 2 & 3 & previsão operacional \\
\hline E_100 & 2 & 3 & influência da relaxação no centro e topo. \\
\hline E_50 & 2 & 3 & influência do aumento do número de camadas dentro da CLP \\
\hline E_R & 2 & 1 & influência da razão $\mathrm{R}\left(\mathrm{k}_{\mathrm{l}} / \mathrm{k}_{\mathrm{m}}\right)=1$ \\
\hline E_K & 1 & 3 & influência da parametrização $K=1$ \\
\hline E_RK & 1 & 1 & Influência de $\mathrm{K}=1$ e $\mathrm{R}\left(\mathrm{k}_{\mathrm{h}} / \mathrm{k}_{\mathrm{m}}\right)=1$ \\
\hline E_2 & 2 & 3 & influência da grade aninhada, como E_50 mas com grade aninhada de $5 \mathrm{~km}$ \\
\hline E_2R & 2 & 1 & influência da grade aninhada, como E_R mas com grade aninhada de $5 \mathrm{~km}$ \\
\hline E_2K & 1 & 3 & influência da grade aninhada, como $E_{-} \mathrm{K}$ mas com grade aninhada de $5 \mathrm{~km}$ \\
\hline E_2RK & 1 & 1 & influência da grade aninhada, como E_RK mas com grade aninhada de $5 \mathrm{~km}$ \\
\hline
\end{tabular}


e 2 misturados (graupel e granizo), é nesta parametrização que se especifica o diâmetro médio para a chuva, neve, agregado, graupel e granizo, a concentração para a nuvem, e também se prevê a concentração para o pristine.

A previsão operacional do GRUMA/UFSM é realizada com a seguinte configuração do BRAMS: uma grade horizontal com $20 \mathrm{~km}$ de resolução (166 pontos em x e 100 pontos em y); espaçamento vertical inicial de $100 \mathrm{~m}$, contendo 36 níveis na vertical até aproximadamente $20 \mathrm{~km}$ (sendo que 8 camadas localizam-se abaixo de $1 \mathrm{~km}$ ); escala de tempo da relaxação no centro do domínio é de 43200s e no topo é de 10800s. A previsão operacional será referida como E_OP.

A metodologia se baseou na alteração sistemática da configuração do BRAMS utilizada na previsão operacional do GRUMA/UFSM buscando-se uma melhoria na simulação do resfriamento noturno (Tabela 1). O primeiro passo foi anular a relaxação no centro e no topo do domínio para fornecer maior liberdade para o modelo BRAMS, realçando os efeitos das alterações feitas nas demais simulações. Esta simulação será referida como E_100. O segundo passo, foi reduzir o espaçamento vertical inicial, passando de $100 \mathrm{~m}$ para $50 \mathrm{~m}$, com o objetivo de aumentar o número de camadas dentro da CLP. Esta redução faz com que o modelo fique com 12 camadas abaixo de $1 \mathrm{~km}$ (antes eram 8). Esta simulação será referida como EXP_50

As duas primeiras alterações apresentadas no parágrafo anterior foram mantidas para o restante das simulações, as quais foram feitas alterando-se 2 opções (Panetta et al., 2002), são elas:

i) o parâmetro referido aqui como K (no RAMSIN é IDIFFK) controla a parametrização usada para se calcular os coeficientes de difusão vertical. Se $\mathrm{K}=1$, o esquema usado é

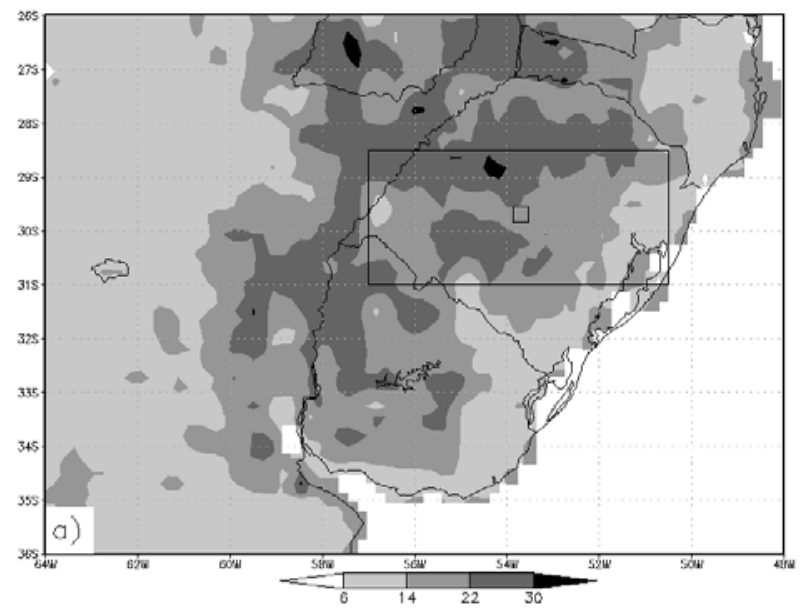

o de Mellor e Yamada (1974), que emprega a energia cinética turbulenta; e se $\mathrm{K}=2$, o esquema usado é o de Smagorinsky (1963) com modificações de Lilly (1962) e Hill (1974), onde a deformação vertical é avaliada a partir do gradiente vertical do vento horizontal e a escala de comprimento vertical é dado pelo produto entre o espaçamento vertical e o parâmetro CSZ. Este último parâmetro serve como um coeficiente no cálculo do coeficiente de difusão vertical. É usado para o cálculo da escala de comprimento difusiva vertical definida como o produto de $\mathrm{CSZ}$ e o espaçamento de grade vertical (neste caso $100 \mathrm{~m}$ ou $50 \mathrm{~m})$. $\mathrm{O}$ valor usado nas simulações foi $\mathrm{CSZ}=0,35$.

ii) o parâmetro R (no RAMSIN é XKHKM ou ZKHKM) indica a razão $\left(\mathrm{k}_{\mathrm{h}} / \mathrm{k}_{\mathrm{m}}\right)$ entre os coeficientes de difusão (horizontal e vertical) para variáveis escalares $\left(\mathrm{k}_{\mathrm{h}}\right)$ e para o momentum $\left(\mathrm{k}_{\mathrm{m}}\right)$. Valores entre $\mathrm{R}=3$ (CLP fortemente convectiva) e $\mathrm{R}=1$ (CLP estável) são indicados.

Uma segunda grade com resolução horizontal de $5 \mathrm{~km}$ foi aninhada à grade operacional de $20 \mathrm{~km}$ para que o modelo resolvesse explicitamente o nevoeiro. Todas as simulações que apresentam o número dois (2) em sua sigla foram realizadas com a segunda grade aninhada. Apesar de se usar duas grades nestas simulações, os gráficos foram gerados utilizando-se a grade 1, pois desta forma a variável no ponto de grade representa um valor médio em um volume igual para quase todas as simulações (exceto para aquelas com espaçamento vertical diferente). Desta forma, pode-se analisar o efeito do aninhamento two-way mas sem reduzir o volume ao qual o ponto de grade representa.

A condição inicial e de contorno lateral foram as mesmas para todas as simulações, ou seja, análise das 0000UTC do dia 17/04/2007 e previsão para 42h do MCG do CPTEC/INPE.

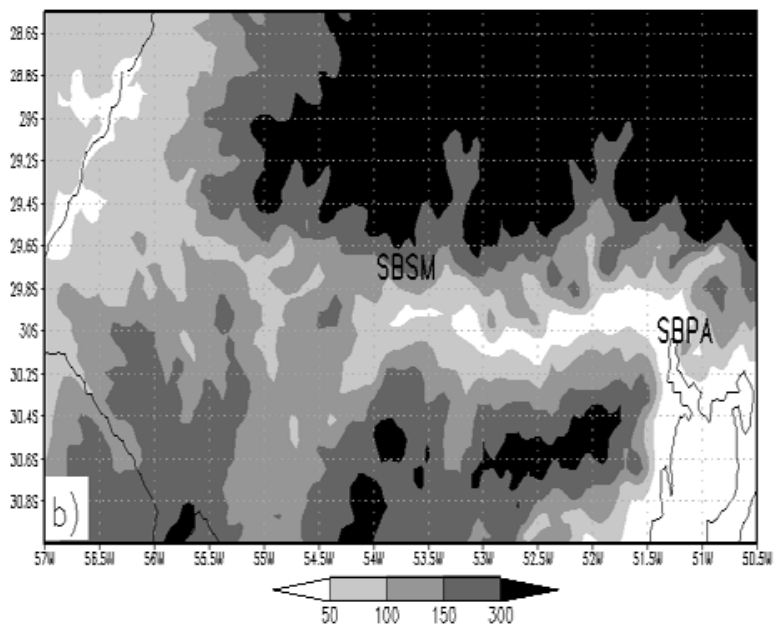

Figura 2 - Em (a) umidade do solo (\%) e em (b) detalhe da topografia (m) usadas nas simulações. Em (a) o quadrado no interior do Estado do Rio Grande do Sul localiza a cidade de Santa Maria e o retângulo indica a área onde a topografia é mostrada em detalhes em (b). Em (b) também estão indicadas a localização das estações SBSM e SBPA (Porto Alegre). 
As condições de contorno inferior (topografia, temperatura da superfície do mar e uso do solo) também foram as mesmas usadas em todas as simulações, destacando-se a umidade do solo (Gevaerd e Freitas, 2006) mostrada na Figura 2a. Observa-se que Santa Maria está em uma área com umidade do solo entre 14 e $22 \%$.

A Figura $2 \mathrm{~b}$ mostra detalhes da topografia da grade com resolução de $5 \mathrm{~km}$. Santa Maria encontra-se na região denominada Depressão Central, entre o Planalto ao norte (com altitudes superiores a $300 \mathrm{~m}$ ) e a Serra do Sudeste. A altitude da estação automática A803 é de $95 \mathrm{~m}$ e o ponto de grade mais próximo encontra-se em $169 \mathrm{~m}$ nas simulações com uma grade, e em $177 \mathrm{~m}$ nas simulações com duas grades.

O período de interesse neste estudo inicia as 1900UTC do dia 17/04/2007 até as 0500UTC do dia 18/04/2007. Este intervalo de $10 \mathrm{~h}$ compreende o período de resfriamento que antecede a formação do nevoeiro, correspondendo ao intervalo entre $19 \mathrm{~h}$ e $29 \mathrm{~h}$ de previsão. Esta escolha baseouse no fato de que a previsão operacional GRUMA/UFSM das 0000UTC torna-se disponível próximo das 1200UTC, ou seja, as primeiras $12 \mathrm{~h}$ de previsão já ocorreram no tempo real. Também se levou em conta que Machado et al. (2007) encontrou maiores erros na análise das 1200UTC, quando comparado a 0000UTC, e mostrou que a análise das 1200UTC apresenta-se mais seca em superfície do que a análise das 0000UTC. Na madrugada do dia 17 também há a ocorrência de nevoeiro, mas este período não será discutido neste artigo.

Nos dia 17 e dia 18 um anticiclone localiza-se sobre o Oceano Atlântico Sul a leste do sul do Brasil (Figura 3a). Esta
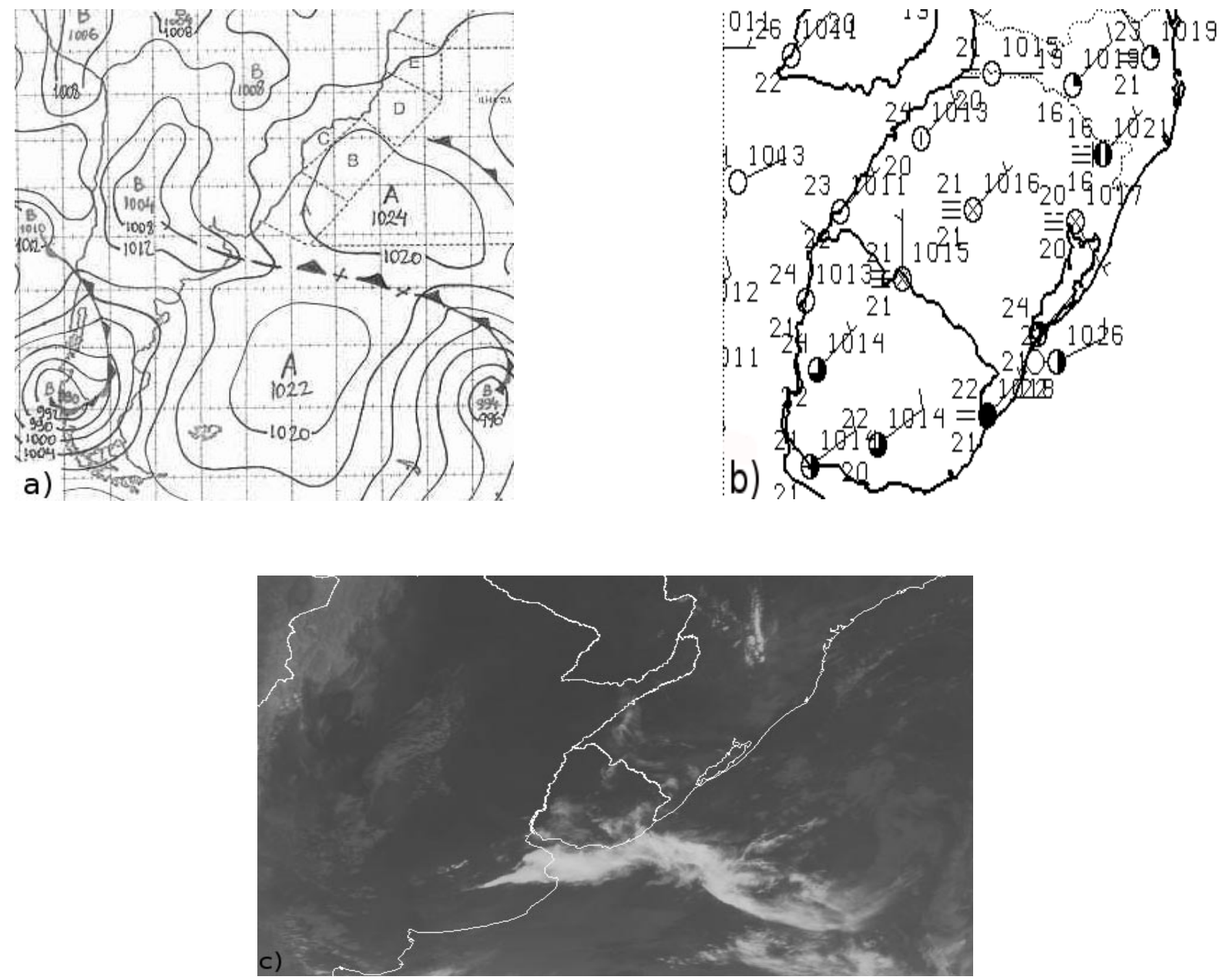

Figura 3 - Detalhe da carta de pressão ao nível do mar (a), da carta SYNOP (b) para as 1200UTC do dia 18 e da imagem infravermelho (c) para as $1145 \mathrm{UTC}$ do dia 18 .

Fonte: DHN (a), CPTEC/INPE (b) e NASA-GSFC (c). 
localização do anticiclone próximo ou sobre o Rio Grande do Sul é favorável ao desenvolvimento do nevoeiro de radiação como registrado por Piva e Fedorova (1999). As 1200UTC do dia 18 pode-se observar na carta que apresenta a mensagem SYNOP, que Santa Maria e Rivera (no Uruguai) registravam a ocorrência de nevoeiro (Figura 3b). Além disso, várias estações registraram céu sem nuvens e com magnitude do vento por volta de $5 \mathrm{~m} / \mathrm{s}$. A imagem no canal infravermelho confirma a ausência de nebulosidade sobre o Rio Grande do Sul e a atuação de uma linha de instabilidade na costa da Argentina (Figura 3c).

O horário estimado da formação do nevoeiro é aproximadamente 0500UTC do dia 18. Para isto utilizaram-se três fontes de informação, são elas: mensagem METAR da estação SBSM, imagens de satélite (produto nevoeiro-stratus) e comportamento das variáveis temperatura e umidade relativa em superfície medido na estação automática. Com base nesta análise verificou-se que Umidade Relativa a $2 \mathrm{~m}$ (UR2m) igual ou superior a $95 \%$ corresponde a ocorrência de nevoeiro em superfície.

A avaliação entre os experimentos e as observações na estação automática foi feita através do erro médio quadrático (RM) e do erro médio (EM, ou viés) dados pelas fórmulas (Wilks, 1995):

$$
\mathrm{RM}=\frac{1}{N} \sum_{n=1}^{N} \sqrt{\left(P_{n}-O_{n}\right)^{2}}
$$

$$
\mathrm{EM}=\frac{1}{N} \sum_{n=1}^{N}\left(P_{n}-O_{n}\right)
$$

onde: P e O são valores previstos e observados, respectivamente, em pares dados no intervalo de $n=1$ a $n=N=11$, representando valores entre as 1900UTC do dia $17 / 04 / 2007$ e as 0500UTC do dia 18/04/2007.

Também calculou-se o índice DIF que representa a diferença da variável (temperatura, umidade relativa ou magnitude do vento) entre as 0500UTC do dia 18 e 1900UTC do dia 17. Estes índices são usados de forma complementar pois o RM informa o valor absoluto do erro característico, enquanto o EM informa o erro médio da previsão, incluindo o sinal que está ausente em RM. Tais índices de maneira geral informam o afastamento entre a curva de previsão e a curva de observação. Já o índice DIF informa a magnitude do resfriamento (no caso da temperatura) ou do umedecimento (no caso da umidade relativa).

\section{RESULTADOS E DISCUSSÃO}

A Figura 4 mostra a evolução temporal da Temperatura (T2m) e da UR2m a $2 \mathrm{~m}$ em Santa Maria, para 42h de previsão operacional (E_OP). O nevoeiro analisado se forma por volta das 0500UTC do dia 18 (correspondendo a 29h de previsão)
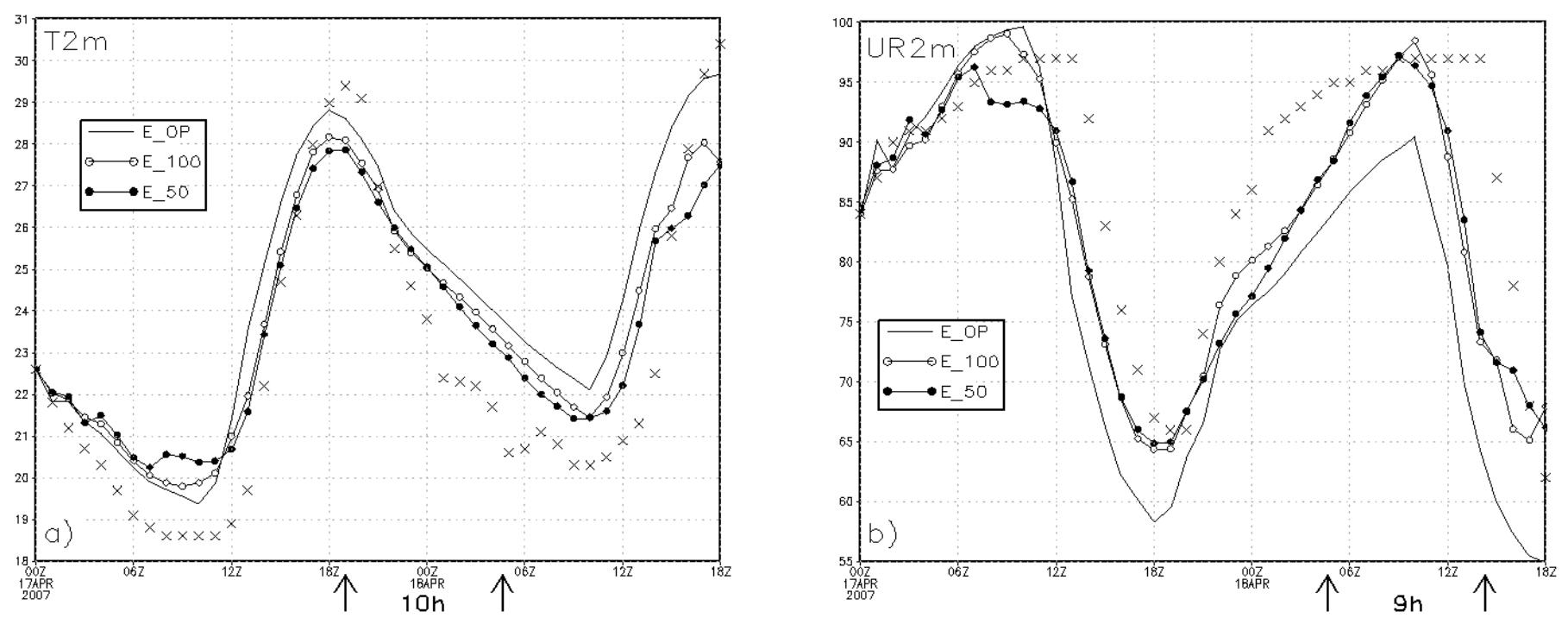

Figura 4 - Evolução da (a) Temperatura $\left({ }^{\circ} \mathrm{C}\right)$ e da (b) Umidade Relativa (\%) em superfície para Santa Maria para a previsão operacional (linha), simulação E_100 (linha com círculo vazio), simulação E_50 (linha com círculo preenchido) e observado (x). Em (a), as setas na parte inferior indicam o período de $10 \mathrm{~h}$ de resfriamento antecedendo o período de $9 \mathrm{~h}$ de ocorrência de nevoeiro, cujo período está indicado pelas setas em (b). 
Tabela 2 - Erros associados as simulações realizadas para as variáveis temperatura (T2m) e umidade relativa (UR2m) a $2 \mathrm{~m}$ e magnitude do vento a 10m (V10m). RM indica o erro médio quadrático, EM o erro médio e DIF indica a diferença.

\begin{tabular}{|c|c|c|c|c|c|c|c|c|c|c|}
\hline \multirow[t]{2}{*}{ Simulaçōes } & \multirow[t]{2}{*}{$\mathrm{K}$} & \multirow[t]{2}{*}{$\mathrm{R}$} & \multicolumn{3}{|c|}{$\begin{array}{l}\text { T2m } \\
\text { (C) }\end{array}$} & \multicolumn{3}{|c|}{$\begin{array}{c}\text { UR2m } \\
\%)\end{array}$} & \multicolumn{2}{|c|}{$\begin{array}{l}\mathrm{V} 10 \mathrm{~m} \\
(\mathrm{~m} / \mathrm{s})\end{array}$} \\
\hline & & & $\mathrm{RM}$ & EMI & DIF & $\mathrm{RM}$ & EM & DIF & $\mathrm{RM}$ & EMI \\
\hline E_OP & 2 & 3 & 1,9 & 1,4 & $-5,0$ & 9,9 & $-9,3$ & 24,7 & 1,1 & 0,7 \\
\hline $\bar{E}$ E_100 & 2 & 3 & 1,6 & 0,9 & $-4,9$ & 6,4 & $-5,5$ & 24,2 & 1,1 & 0,7 \\
\hline E_50 & 2 & 3 & 1,5 & 0,7 & $-5,0$ & 7,5 & $-6,5$ & 23,5 & 0,9 & 0,5 \\
\hline E_R & 2 & 1 & 2,0 & 0,7 & $-3,1$ & 10,4 & $-7,9$ & 12,5 & 1,0 & 0,6 \\
\hline E_K & 1 & 3 & 1,5 & 0,9 & $-5,6$ & 6,3 & $-5,5$ & 26,3 & 0,8 & 0,4 \\
\hline E_RK & 1 & 1 & 1,4 & 0,7 & $-5,5$ & 4,3 & $-3,3$ & 25,6 & 0,8 & 0,3 \\
\hline E_2 & 2 & 3 & 1,8 & 1,1 & $-4,8$ & 8,8 & $-7,8$ & 23,7 & 0,9 & 0,3 \\
\hline E_2R & 2 & 1 & 1,7 & 0,7 & $-4,2$ & 6,8 & $-5,7$ & 21,3 & 0,8 & $-[0,1$ \\
\hline E_2K & 1 & 3 & 1,7 & 1,3 & $-5,7$ & 8,7 & $-8,0$ & 27,1 & 1,0 & 0,5 \\
\hline E_2RK & 1 & 1 & 1,5 & 1,0 & $-5,7$ & 6,3 & $-5,6$ & 27,1 & 0,9 & 0,5 \\
\hline
\end{tabular}

e se dissipa as 1400UTC do mesmo dia. Este período de $9 \mathrm{~h}$ com nevoeiro está indicado na parte inferior da Figura $4 \mathrm{~b}$, e caracteriza-se por UR2m igual ou superior a $95 \%$. O período de $10 \mathrm{~h}$ de resfriamento (Figura $4 \mathrm{a}$ ) e de aumento de umidade relativa (Figura 4b) entre 1900UTC do dia 17 e 0500UTC do dia 18 está indicado pelas setas na parte inferior da Figura 4a. $\mathrm{Na}$ previsão operacional, $\mathrm{T} 2 \mathrm{~m}$ tem uma taxa de resfriamento de $-5,0^{\circ} \mathrm{C} / 10 \mathrm{~h}$, enquanto nos dados observados esta taxa é de $-8,8^{\circ} \mathrm{C} / 10 \mathrm{~h}$. A variável UR2m apresenta uma taxa de $24,7 \% / 10 \mathrm{~h}$ na previsão operacional enquanto os dados observados mostram uma taxa de 29\%/10h. Piva e Fedorova (1999) em um estudo observacional de 11 situações de nevoeiro para Porto Alegre mostraram que as taxas de resfriamento variaram entre $-0,5^{\circ} \mathrm{C} / \mathrm{h}$ $\left(-5^{\circ} \mathrm{C} / 10 \mathrm{~h}\right)$ e $-1,2^{\circ} \mathrm{C} / \mathrm{h}\left(-12^{\circ} \mathrm{C} / 10 \mathrm{~h}\right)$. As taxas de aumento de umidade relativa observadas por eles oscilaram entre $0,5 \% / \mathrm{h}$ $(5 \% / 10 \mathrm{~h})$ e $3,8 \% / \mathrm{h}(38 \% / 10 \mathrm{~h})$.

Nos dados da estação automática, o período com UR2m igual ou superior a $95 \%$ foi de $9 \mathrm{~h}$, mas na previsão operacional a UR2m foi no máximo de $90 \%$, caracterizando a ausência de formação do nevoeiro de radiação em superfície na previsão operacional.

A Tabela 2 mostra os erros e as taxas de resfriamento e umedecimento obtidas nas simulações realizadas. De forma geral, pode-se observar que o modelo tende a superestimar a temperatura entre $0,7^{\circ} \mathrm{C}$ a $1,4^{\circ} \mathrm{C}$ com relação aos dados em superfície. A umidade relativa tende a ser subestimada entre $3,3 \%$ e $-9,3 \%$ e a magnitude do vento tende a ser superestimada entre $0,3 \mathrm{~m} / \mathrm{s}$ e $0,7 \mathrm{~m} / \mathrm{s}$ (com exceção de uma simulação em que foi obtido viés igual a $-0,1 \mathrm{~m} / \mathrm{s}$ ).

Como apresentado na metodologia, o primeiro passo foi anular a relaxação no centro e no topo do domínio (simulação E_100) e aumentar o número de camadas em baixos níveis (simulação E_50). Estas mudanças tendem a reduzir os erros (RM e EM) para T2m, UR2m e V10m (magnitude do vento a $10 \mathrm{~m}$ ), mas DIF permanece inalterado ou piora com relação a $E_{-}$ OP (Tabela 2). Um comportamento diferente também pode ser notado nas variáveis $T 2 \mathrm{~m}, \mathrm{~V} 10 \mathrm{~m}$ e UR2 $\mathrm{m}$, entre as simulações E_100 e E_50. Para a variável T2m e V10m percebe-se que os erros diminuem com relação a $\mathrm{E} \_100$, quando se aumenta o número de camadas nos baixos níveis, mas o contrário ocorre com a UR2m. Por exemplo, o EM da UR2m foi de $-9,3 \%$ em E_OP, diminuindo para $-5,5 \%$ em E_100 e aumentando para $-6,5 \%$ em E_50. Diferentemente de T2m que diminuiu de $1,4^{\circ} \mathrm{C}$ em E_OP para $0,9^{\circ} \mathrm{C}$ e $0,7^{\circ} \mathrm{C}$ em E_100 e E_50, respectivamente.

Na Figura 4 também pode-se verificar a evolução de T2m e UR2m para as simulações E_100 e E_50, juntamente com E_OP e as observações. Como indicam os erros para T2m e UR2 $m$, a distância entre a curva simulada e observada diminuiu 


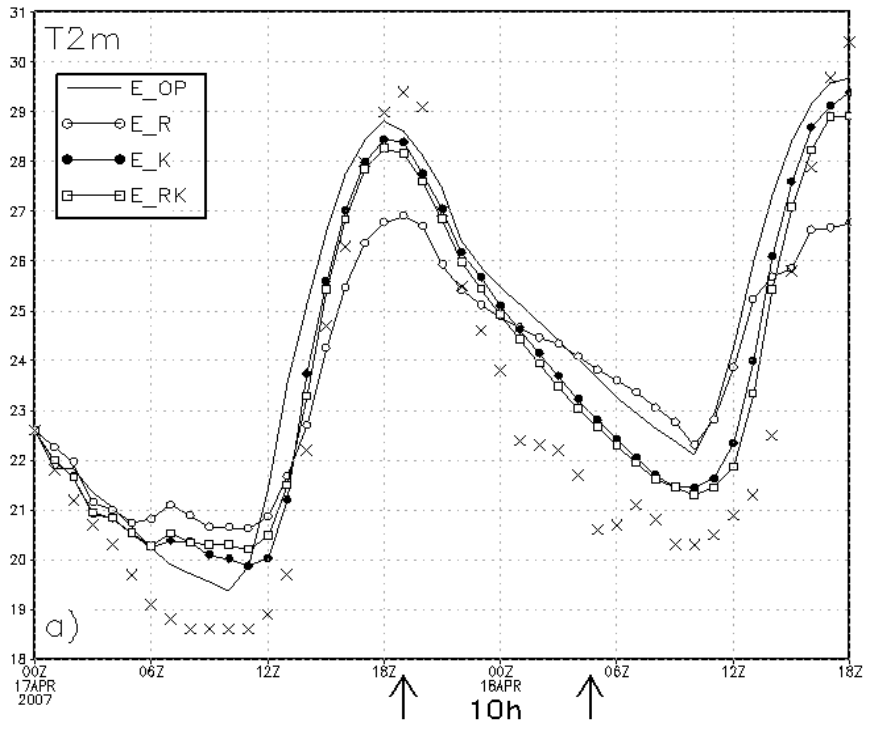

Figura 5 - Como na Figura 4, mas para as simulações E_R, E_K e E_RK.

com as mudanças realizadas. Nota-se que, a UR2m atingiu valores iguais ou superiores a $95 \%$ com estas duas alterações, chegando a $4 \mathrm{~h}$ com nevoeiro.

Nas simulações E_R, E_K e E_RK (Tabela 2), observase que ao se alterar a razão $\mathrm{R}$ de 3 para 1, pioram os resultados, ou seja $\mathrm{RM}=2^{\circ} \mathrm{C}$ para $\mathrm{T} 2 \mathrm{~m}$ e $10,4 \%$ para UR2m. Entretanto, deve-se ressaltar que o manual do BRAMS indica que o valor $\mathrm{R}=1$ é apropriado para situações de CLP estável, situação típica para a formação de nevoeiro de radiação. Tal inconsistência pode residir no fato de que antes do período de estabilidade noturna, ocorreu um período diurno com CLP convectiva, degradando os resultados da simulação com $\mathrm{R}=1$. Isto de fato ocorre como indica a Figura 5. Nota-se que a curva do experimento E_R (círculo aberto) se distancia das observações e dos demais experimentos durante o período mais quente do dia (por volta das 1800UTC), que se caracteriza por CLP convectiva. Supõe-se que a opção $\mathrm{R}=1$ forneça bons resultados, quando durante toda a simulação a atmosfera se encontra estável. A simulação E_K apresenta bons resultados, principalmente para a UR2m $(\mathrm{RM}=6,3 \%)$. Entre as simulações apresentadas até agora, a maior queda de temperatura $\left(\mathrm{DIF}=-5,6^{\circ} \mathrm{C} / 10 \mathrm{~h}\right)$ e o maior aumento de umidade ( $D I F=26,3 \% / 10 \mathrm{~h}$ ) foi obtido com E_K, mas ainda foram abaixo dos valores observados ($8,8^{\circ} \mathrm{C} / 10 \mathrm{~h}$ para T2m e $29 \% / 10 \mathrm{~h}$ para UR2m). E_RK apresenta o melhor resultado em termos de erro $\left(\mathrm{RM}=1,4^{\circ} \mathrm{C}\right.$ para $\mathrm{T} 2 \mathrm{~m}$ e $4,3 \%$ para UR2m) no caso de experimentos com apenas uma grade, o que representa um resultado inesperado pois quando somente a opção $\mathrm{R}=1$ foi aplicada (E_R) observou-se os piores resultados. Tal resultado sugere que a opção $\mathrm{R}=1$ deve ser usada somente com o esquema de Mellor-Yamada $(\mathrm{K}=1)$.

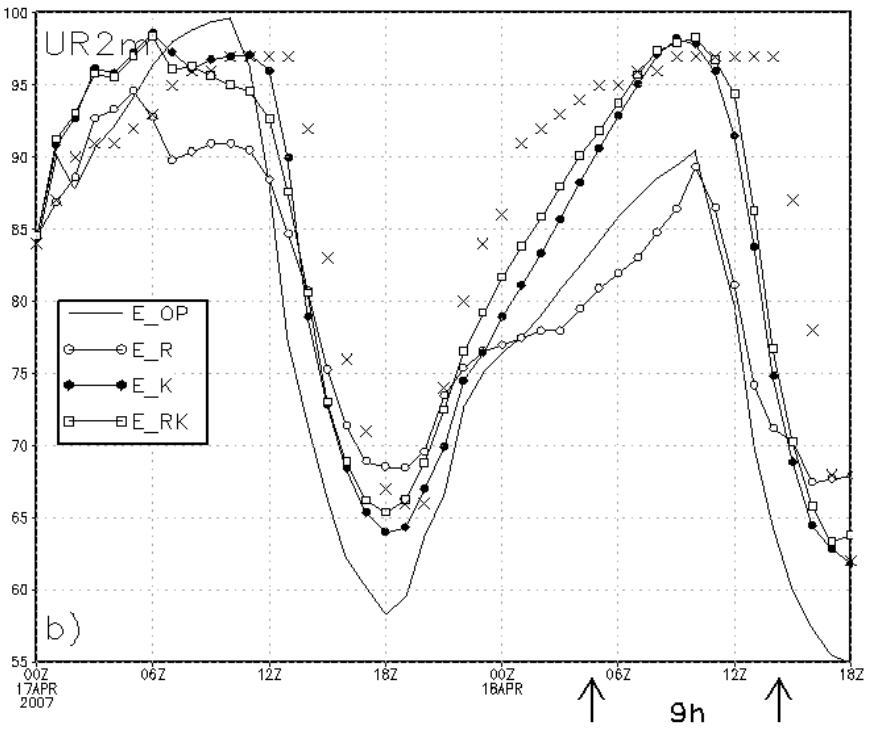

A Figura 5b mostra que os experimentos E_K e E_RK resultaram em UR2m igual ou superior a $95 \%$ durante $5 \mathrm{~h}$, indicando a presença de nevoeiro em superfície. Ressalta-se que este resultado não está associado ao aumento das taxas de umedecimento (resfriamento) no período anterior ao nevoeiro, mas sim a redução do erro na simulação da UR2m mínima (T2m máxima) verificada por volta da hora mais quente do dia (aproximadamente 1800UTC).

A Figura 6a mostra o perfil de temperatura para as simulações E_OP e E_K para as 2100UTC (sem nevoeiro) do dia 17 e para as 0900UTC (com nevoeiro) do dia 18. Há maior resfriamento em E_K em relação a E_OP e o estabelecimento de uma camada de inversão térmica, indicada pelas setas a esquerda da Figura 6a. A presença de uma inversão térmica em situações de nevoeiro de radiação é normalmente observada, porém a base da inversão se encontra em superfície, diferentemente dos resultados aqui obtidos, os quais indicam que a base da inversão encontra-se em 350m.

A evolução do perfil da umidade relativa no experimento E_RK pode ser vista na Figura 6b. Nota-se o aumento da umidade relativa a partir das 18 (1800UTC do dia 17) desde a superfície até $550 \mathrm{~m}$. Em torno de $350 \mathrm{~m}$ localiza-se o maior aumento de umidade relativa, o que pode estar associado ao fato de que em superfície ocorreu deposição de orvalho, reduzindo a umidade próxima à superfície. Tal situação é comum em nevoeiros de radiação, quando há desenvolvimento de inversão no perfil vertical da temperatura do ponto de orvalho (Cotton e Anthes, 1989). Para comparação, também está apresentado o perfil de umidade relativa para dois horários (18 e 12) para a simulação E_OP. Verifica-se que em E_OP o aumento de 
umidade relativa é bem menor do que em E_RK, além de não haver inversão no perfil.

Com a inclusão da segunda grade (E_2, E_2R, E_2K, E_2KR), nota-se que há leve piora nos resultados relativos a $\mathrm{RM}$ e EM, mas um leve aumento em DIF (para $\mathrm{T} 2 \mathrm{~m}=-5,7^{\circ} \mathrm{C}$ e $\mathrm{UR} 2 \mathrm{~m}=27,1 \%$ ). Pode-se notar pela Figura 7, que o maior erro foi associado aos melhores resultados no período de máximo aquecimento obtidos pelas simulações com duas grades, quando comparadas às respectivas simulações com apenas uma grade. Este paradoxo ocorre, pois entre o máximo de T2m (por volta das 1900UTC) e o mínimo (por volta das 1000UTC) a curva da temperatura simulada cruza as observações durante o resfriamento, e como nas simulações com 2 grades as temperaturas simuladas foram mais próximas das observadas, a curva simulada cruza as observações antes do que nas simulações com apenas uma grade. Desta forma a curva simulada se afasta das observações em maior grau nas simulações com 2 grades do que com 1 grade, resultando em erros maiores.

$\mathrm{Na}$ evolução da UR2m, pode-se notar que a inclusão da segunda grade reduz a duração do nevoeiro em superfície em aproximadamente $1 \mathrm{~h}$. O erro neste caso está associado ao fato de que no período de mínima UR2m (por volta das 1900UTC), as simulações com duas grades geraram UR $2 \mathrm{~m}$ bem abaixo das

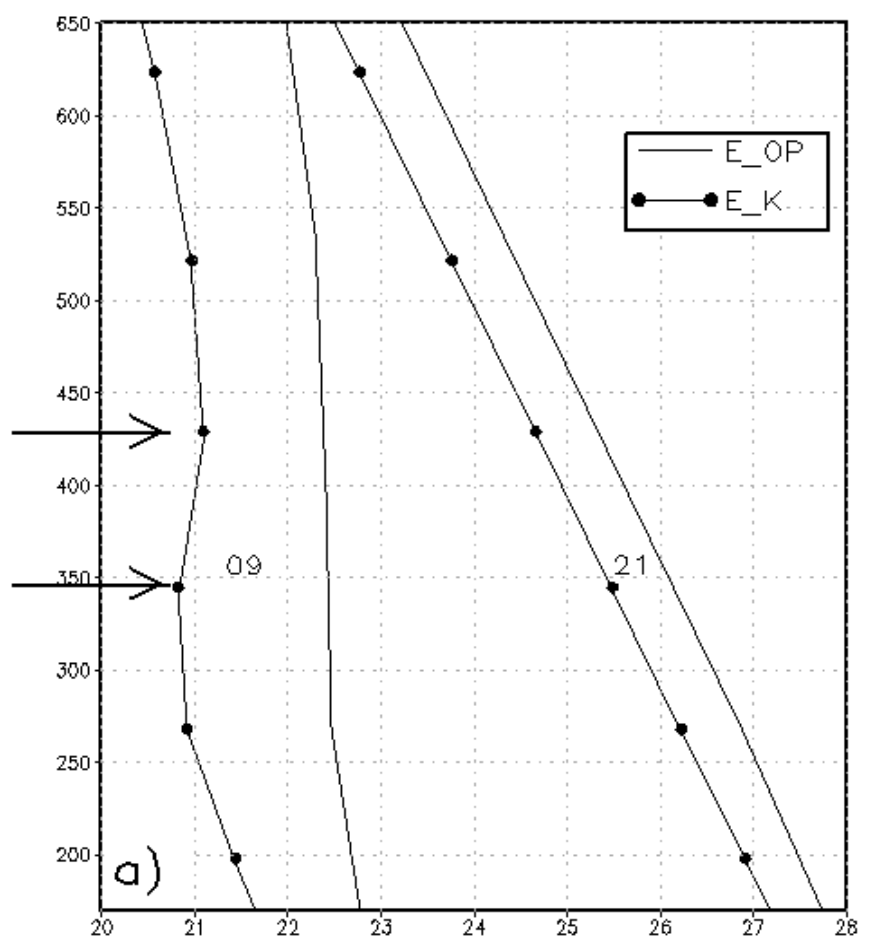

observadas e das simuladas com apenas uma grade, e como a taxa de umedecimento é menor do que a observada e próxima das taxas simuladas com apenas uma grade, a UR2m levou mais tempo para alcançar UR2m igual a 95\%. Fora isso, deve-se destacar que a segunda grade permite resolver explicitamente o nevoeiro em superfície, ou seja, incluindo a ocorrência de nevoeiro, há alteração em todo o balanço de energia (T2m) e de umidade (UR2m).

A Figura 8 mostra gráficos tempo versus altura da razão de água líquida, das 0500UTC as 1400UTC do dia 18 para as simulações E_50 e E_2RK. Observa-se que valores de conteúdo de água líquida igual ou superior a $0,02 \mathrm{~g} / \mathrm{kg}$, o que segundo Cotton e Anthes (1989) é valor típico de nevoeiro, ocorrem somente acima de $250 \mathrm{~m}$ ( $74 \mathrm{~m}$ acima da superfície terrestre) na simulação E_50 (em E_OP o conteúdo de água líquida foi zero), mas em E $2 R K$ este valor ocorre em superfície, caracterizando a ocorrência de nevoeiro em superfície. Destaca-se que o conteúdo de água líquida em superfície igual ou superior a $0,02 \mathrm{~g} / \mathrm{kg}$, só foi encontrado nos experimentos que usaram o esquema de Mello-Yamada $(\mathrm{K}=1)$, ou seja, E_RK, E_2K e E_2RK.

Todas as simulações com uma grade apresentam os máximos de razão de água líquida maiores do que as simulações com duas grades. O máximo de menor valor foi de $0,16 \mathrm{~g} / \mathrm{kg}$

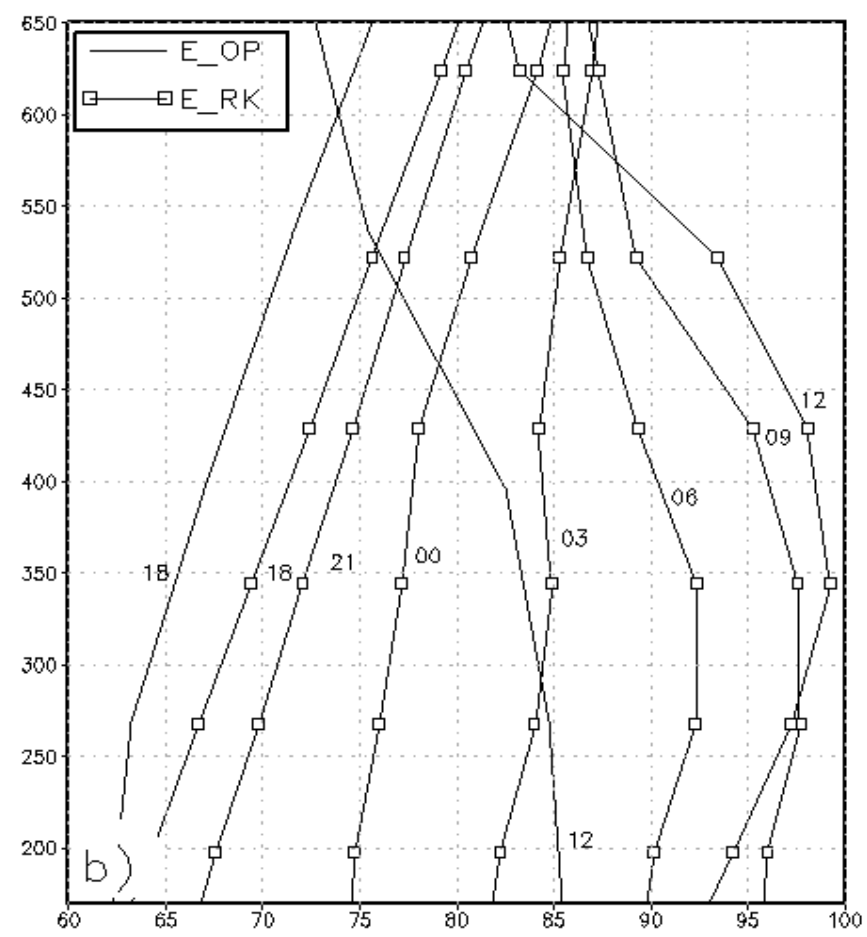

Figura 6 - Em (a) perfil de temperatura (oC) com nevoeiro as 0900UTC (09) e sem nevoeiro as 2100UTC (21) em Santa Maria para E_0P (linha contínua) e E_K (linha contínua com círculo preenchido). Em (b), perfil de umidade relativa (\%) para E RK (linha contínua com quadrado vazio) para vários horários entre 1800UTC (18) do dia 17 e 1200UTC (12) do dia 18; e para a simulação E_OP (linha contínua) para as 1800UTC (18) do dia 17 e $1200 \mathrm{UTC}(12)$ do dia 18. 

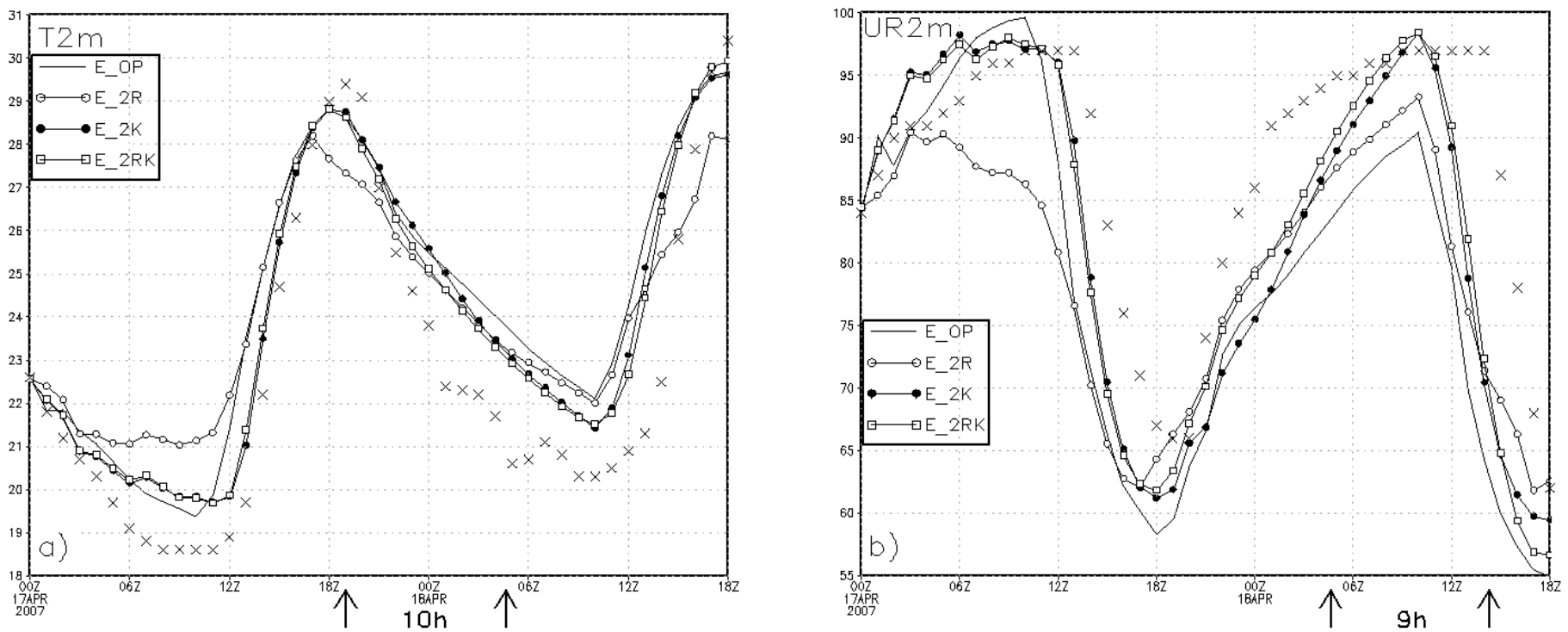

Figura 7 - Como na Figura 4, mas para as simulações E_2R, E_2K e E_2RK.
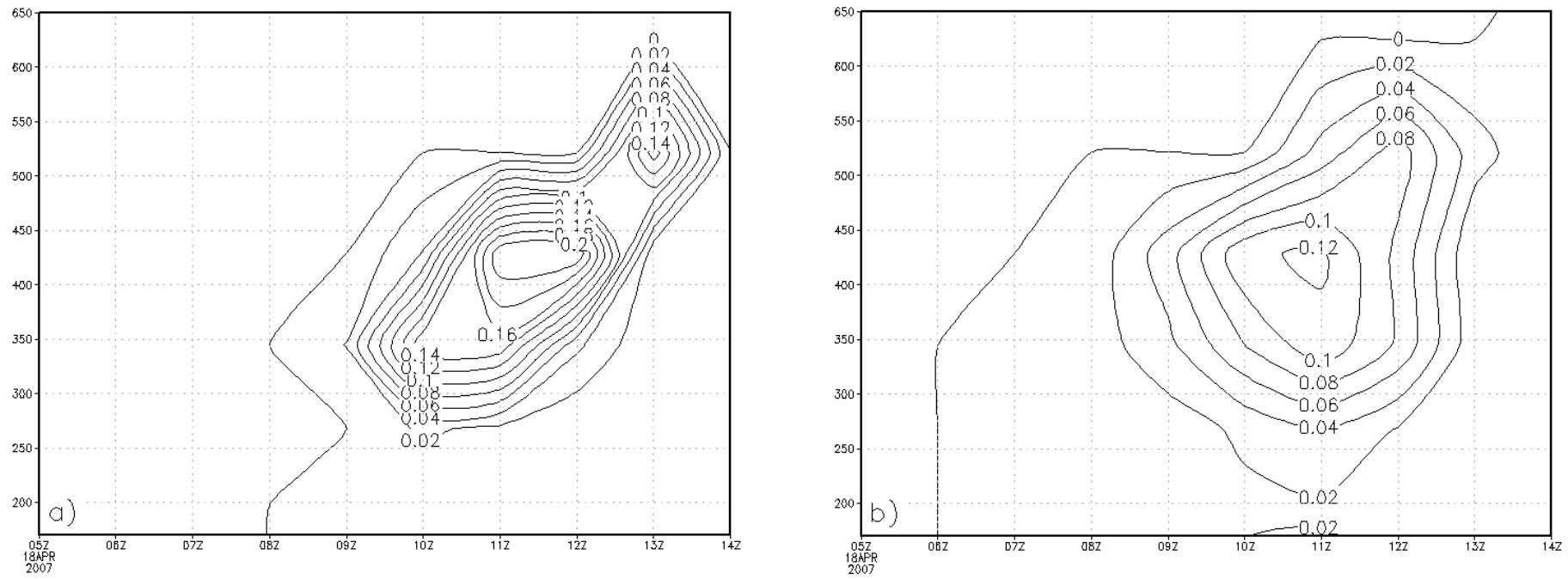

Figura 8 - Gráfico tempo versus altura da razão de mistura de água liquida (g/kg) em Santa Maria para as simulações E_50 (a) e E_2RK (b).

(E_100) e o maior foi de $0,4 \mathrm{~g} / \mathrm{kg}$ (E_RK), em altitudes que variaram de $340 \mathrm{~m}$ a $400 \mathrm{~m}$, ou seja, acima de $160 \mathrm{~m}$ da superfície. Este comportamento pode ser em parte explicado pela menor turbulência simulada quando se usa duas grades. Como indicado pela Figura 9, na simulação com duas grades (E_2RK) a magnitude do vento torna-se menor do que na simulação com uma grade (E_RK) em quase todos os níveis e tempos. Em um ambiente com ventos mais fracos, também a turbulência e a difusão de umidade para cima são mais fracos.

O horário com maior UR2 $m$ na simulação E_2RK foi as 1100UTC do dia 18, sendo assim, na Figura 10 está representado o campo de UR2m neste horário para as simulações E_OP (a) e E_2RK (b). Pode-se observar que em E_OP a UR2m igual ou superior a $95 \%$ esteve restrita às áreas próximas a Lagoa dos Patos e nos vales dos rios Jacuí, Taquari-Antas e Caí, próximo a Porto Alegre (SBPA). Em E_2RK observa-se uma extensa área com UR2m igual ou superior a 95\% ao longo da Depressão Central e estendendo-se também para o vale do Rio Uruguai, indicando assim nevoeiro sobre estas áreas.

Em situações de nevoeiro, é comum a direção do vento ao longo da Depressão Central adquirir direção de leste (J. L. Fontinele, 2007, comunicação pessoal). Tal escoamento 
pode fornecer umidade para a formação do nevoeiro, pois à leste-sudeste de Santa Maria encontra-se a bacia do Rio Vacacaí, que se caracteriza por apresentar extensas áreas alagadas com plantações de arroz. Tal comportamento foi observado nas simulações realizadas neste estudo como indica a Figura 11. Em ambas as simulações (E_OP e E_2RK) no horário das 0800UTC do dia 18, observa-se um escoamento de leste ao longo da Depressão Central, mas no primeiro experimento o escoamento parece estar mais canalizado que no segundo. Contrariando as expectativas, na simulação com maior resolução espacial (vertical e horizontal) a topografia apresentou menor impacto na canalização do escoamento do que na simulação com menor resolução espacial. Apesar disso, pode-se observar que o escoamento apresentou-se levemente mais fraco na simulação com duas grades do que com uma grade.

\section{CONCLUSÕES}

Foram realizadas simulações com o BRAMS versão 3.2 , com o objetivo de reproduzir a forte taxa de resfriamento

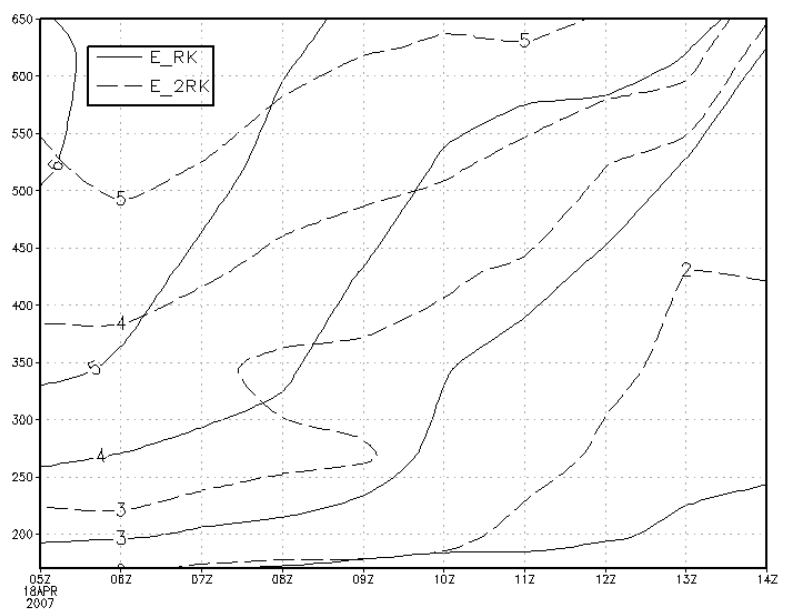

Figura 9 - Como na Figura 8, mas para a magnitude do vento (m/s) nas simulações E_RK (contínua) e E_2RK (tracejado).
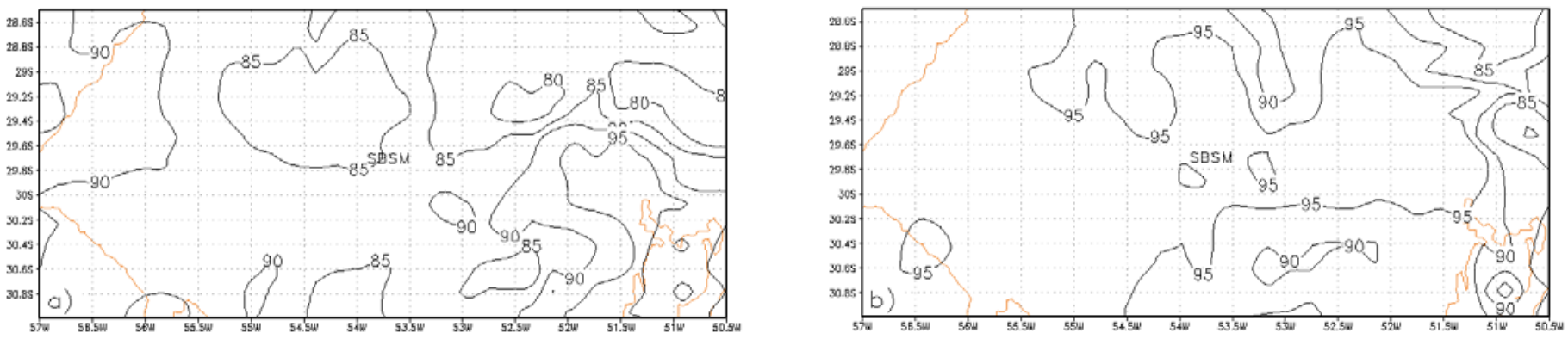

Figura 10 - Campo de UR2m (\%) as 1100UTC do dia 18 para as simulações E_OP (a) e E_2RK (b).
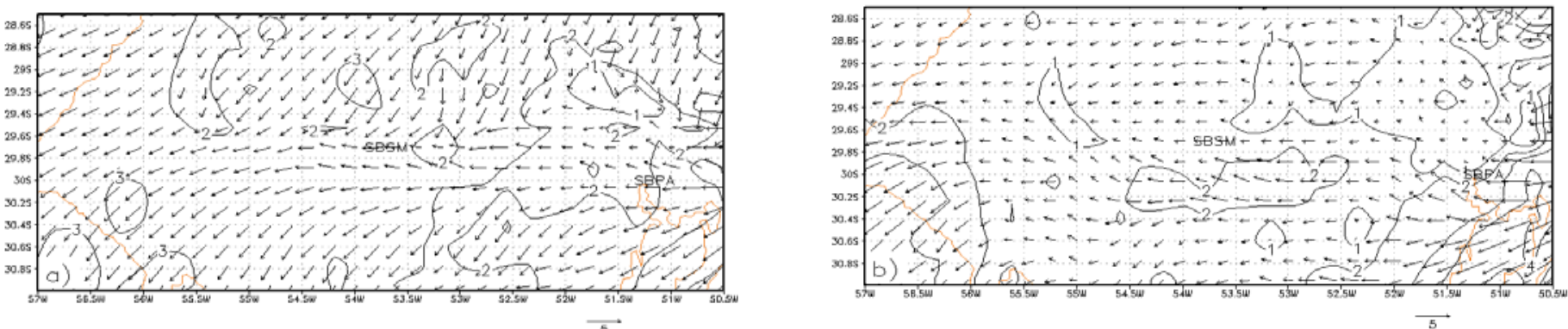

Figura 11 - Como na Figura 10, mas para o campo de $\overrightarrow{\mathrm{V}} 10 \mathrm{~m}(\mathrm{~m} / \mathrm{s})$ as $0800 \mathrm{UTC}$ do dia 18. 
noturno associada à formação de nevoeiro de radiação ocorrido na madrugada do dia 18/04/2007 na cidade de Santa Maria. Parâmetros e parametrizações relacionados à turbulência foram alterados em uma série de simulações, que usaram a mesma condição inicial, de contorno inferior e de contorno lateral.

De acordo com os resultados obtidos, pode-se concluir:

- Com relação aos dados observados na estação automática de superfície, o modelo tende a superestimar a temperatura e a magnitude do vento e de subestimar a umidade relativa;

- Com relação a previsão operacional, anular a relaxação no centro e no topo do domínio melhora os resultados relacionados a temperatura, umidade relativa e magnitude do vento em superfície;

- Com relação a previsão operacional, aumentar o número de camadas dentro da camada limite planetária melhora os resultados relacionados a temperatura e magnitude do vento, mas não para a umidade relativa;

- Para simulações com uma grade, o melhor resultado em termos de erro (erro médio quadrático e erro médio) foi obtido com a parametrização de Mellor-Yamada associada com a razão (entre os coeficientes de difusão para variáveis escalares e para o momentum) igual a 1 (simulação referida como E_RK);

- Para simulações com uma grade, o melhor resultado para taxa de resfriamento $\left(-5,6^{\circ} \mathrm{C} / 10 \mathrm{~h}\right)$ e taxa de aumento de umidade $(26,3 \% / 10 \mathrm{~h})$ foi obtida com a parametrização de Mellor-Yamada e com a razão igual a 3 (simulação referida como $\mathrm{E}_{-} \mathrm{K}$ ). Porém estas taxas ainda foram inferiores às observadas, sendo de $-8,8^{\circ} \mathrm{C} / 10 \mathrm{~h}$ para a temperatura e de $29 \% / 10 \mathrm{~h}$ para a umidade relativa;

- Para simulações com uma grade, a opção $\mathrm{R}=1$ só gera resultados aceitáveis, quando associado ao esquema de MellorYamada, já $\mathrm{R}=3$ gera bons resultados para ambos os esquemas (Mellor-Yamada e Smgorinsky);

- Para a simulação com uma grade que resultou em maior resfriamento em superfície, o perfil vertical de temperatura mostrou uma inversão, mas esta não apresentou sua base na superfície como é comum em situações de nevoeiro de radiação;

- Para a simulação com uma grade que resultou em menores erros em termos de umidade relativa, o perfil vertical de umidade relativa também mostrou o desenvolvimento de uma inversão, indicando que nas camadas mais baixas a deposição de orvalho na superfície pode ter reduzido a umidade atmosférica;

- Para simulações com duas grades, de modo geral, há piora nos resultados quando comparadas às simulações com apenas uma grade;

- Para simulações com duas grades, os menores erros, a maior taxa de resfriamento $\left(-5,7^{\circ} \mathrm{C} / 10 \mathrm{~h}\right)$ e a maior taxa de aumento de umidade $(27,1 \% / 10 \mathrm{~h})$ em superfície foram obtidos com o esquema de Mellor-Yamada e razão 1 entre os coeficientes. Porém, ainda foram inferiores às taxas observadas;

- Para simulações com duas grades, relativamente bons resultados são obtidos com a simulação que emprega o esquema de Smagorinsky e razão 1 entre os coeficientes, diferentemente do obtido com apenas uma grade. Isto sugere que com resolução horizontal cada vez maior, o esquema de Smagorinsky pode se comportar melhor do que o esquema de Mellor-Yamada;

- Para a simulação com duas grades e que apresentou os melhores resultados (E_2RK, com Mellor-Yamada e $\mathrm{R}=1$ ), a razão de mistura de água líquida em superfície atingiu valores da ordem de $0,02 \mathrm{~g} / \mathrm{kg}$, indicando a presença de nevoeiro em superfície.

- Os dados observados de umidade relativa em superfície indicam que houve $9 \mathrm{~h}$ de nevoeiro, mas os melhores resultados ( $5 \mathrm{~h}$ de nevoeiro) foram obtidos com as simulações que empregarm apenas uma grade, o esquema de Mellor-Yamada e as razões 1 ou 3 entre os coeficientes;

As opções do BRAMS abordadas neste estudo (relaxação no centro e no topo do domínio, resolução vertical e horizontal, esquemas de cálculo dos coeficientes de difusão vertical e razão entre coeficientes de difusão para escalares e para o momentum) geraram pequenas melhoras em termos de resfriamento ou umedecimento, mas foram suficientes para formar o nevoeiro como indicam as $5 \mathrm{~h}$ com umidade relativa em superfície igual ou superior a $95 \%$ e a presença de razão de água líquida em torno de $0,02 \mathrm{~g} / \mathrm{kg}$ também em superfície. Na mesma linha de pensamento deste artigo, mas abordando outros aspectos do BRAMS, podem ser desenvolvidos estudos comparativos abordando os diferentes dados de contorno inferior, tais como umidade do solo, mapas de uso e cobertura do solo e dados de NDVI, os quais são de extrema importância para a correta previsão de nevoeiros. Também podem ser estudadas as parametrizações de radiação disponíveis no modelo, pois o nevoeiro de radiação depende da correta previsão da perda radiativa por ondas longas. Além disso, na previsão operacional pode-se empregar modelos específicos, tais como os modelos unidimensionais de camada limite, os quais são modelos desenhados exclusivamente para representar a camada limite noturna. $\mathrm{O}$ modelo francês COBEL (Couche Brouillard Eau Liquide) é um bom exemplo a ser citado, este utiliza informações de mesoescala (campo de vento geostrófico, advecção de temperatura e umidade) fornecidas por um modelo de mesoescala, e parametriza processos de troca entre solo e atmosfera, incluindo seis variáveis prognósticas (temperatura, razão de mistura, duas componentes do campo de vento, água líquida e energia cinética turbulenta) que são discretizadas em 30 níveis entre a superfície e 1400m (Guedalia e Bergot, 1994). Tal modelo também inclui parametrização de orvalho, geada e de radiação de onda longa. 
Outra possibilidade seria a implementação de uma parametrização turbulenta mais apropriada a camada limite estável (noturna) no BRAMS, pois à princípio, este é o único processo físico não parametrizado pelo BRAMS quando comparado ao COBEL. Lee et al (2006) identificaram que a deficiência das parametrizações de turbulência disponíveis nos modelos MRF (Medium Range Forecast) e MM5 é, em parte, devido ao fato das parametrizações considerarem a razão $\mathrm{R}$ (ou o inverso do número de Prandtl turbulento) como sendo constante. As duas parametrizações propostas por Lee et al (2006) garantem que a razão R seja variável, concordando com os dados observados obtidos em situações de forte estabilidade térmica, o que é característico do período com forte resfriamento noturno. A razão $R$ variável foi obtida calculando-se $k_{h}$ e $k_{m}$ independentemente, sendo ambos função da estabilidade térmica. Nesta situação, a difusão de momentum pode ocorrer por ondas internas, ao mesmo tempo que a difusão de calor por vórtices turbulentos é suprimida pela estratificação estável. Na versão 3.2 do BRAMS, há uma opção de parametrização turbulenta $($ IDIFFK $=4)$ em que a razão $R$ é calculada automaticamente para cada ponto de grade e dependente das condições locais, mas esta opção só pode ser aplicada quando o espaçamento horizontal for da ordem do espaçamento vertical. Neste caso, a estabilidade numérica é garantida através de um passo de tempo muito pequeno, fazendo com que o tempo de execução de uma previsão de curto-prazo torne-se longo o suficiente para impedir o uso desta opção na previsão operacional de tempo.

Sendo assim, a implementação e avaliação de um modelo unidimensional (ex. COBEL) ou a implementação no BRAMS de uma parametrização turbulenta apropriada para a camada limite noturna são duas possibilidades para a melhoria na previsão de nevoeiro de radiação na cidade de Santa Maria.

\section{AGRADECIMENTOS}

Agradecemos a CAPES (processo número 7920) e ao $\mathrm{CNPq}$ (processo número 381246/2007-8) pelo apoio financeiro concedido. Também agradecemos ao CPTEC/INPE, DSA-CPTEC/INPE, INMET, DHN, MASTER-IAG/USP, Aeronáutica e NASA-GSFC por disponibilizar gratuitamente pela rede mundial de computadores, dados, informações e imagens sem as quais este estudo não poderia ser realizado.

\section{REFERÊNCIAS BIBLIOGRÁFICAS}

CHEN, C.; COTTON, W. R. A one-dimensional simulation of the stratocumulus-capped mixed layer. Boundary-Layer Meteorology, v. 25, p. 289-321, 1983.

COTTON, W. R.; ANTHES, R. A. Storm and cloud dynamics. San Diego: Academic Press, 1989. 880 p.
COTTON, W. R.; PIELKE, R. A.; WALKO, R. L.; LISTON, G. E.; TREMBACK, C. J.; JIANG, H.; MCANELLY, R. L.; HARRINGTON, J. Y.; NICHOLLS, M. E.; CARRIO, G. G.; MCFADDEN, J. P. RAMS 2001: Current status and future directions. Meteorology and Atmospheric Physics, v. 82, p. 5-29, 2003.

FAZENDA, A. L.; MOREIRA, D. S.; ENARI, E. H.; PANETTA, J. First time user's guide (BRAMS version 3.2). Cachoeira Paulista, 2006. 24p.

GEVAERD, R;FREITAS, S. R. Estimativa operacional da umidade do solo para iniciação de modelos de previsão numérica da atmosfera. Parte I: Descrição da metodologia e validação. Revista Brasileira de Meteorologia, v. 21, n. 3a, p. 59-73, 2006. GUEDALIA, D.; BERGOT, T. Numerical Forecasting of Radiation Fog. Part II: A comparation of Model simulation with several observed fog events. Monthy Weather Review, v. 122, p. 1231-1246, 1994.

HILL, G. E. Factors controlling the size and spacing of cumulus clouds as revealed by numerical experiments. Journal of the Atmospheric Science, v. 31, p. 646-673, 1974.

LEE, S. M.; GIORI, W.; PRINCEVAC, M.; FERNANDO H. J. S. Implementation of a stable PBL turbulence parameterization for the mesoescale model MM5: nocturnal flow in complex terrain, Boundary-Layer Meteorology, v. 119, p. 109-134, 2006.

LIMA, J. S. Previsão de ocorrência de nevoeiro em Porto Alegre: método objetivo. Instituto de Proteção ao Vôo do Ministério da Aeronáutica, 1982.18p.

LILLY, D. K. On the numerical simulation of buoyant convection. Tellus, v. XIV, p. 148-172, 1962.

MACHADO, V. B.; PIVA, E. DAL; ACEVEDO, O. C. A.; MORAES, O. L. de, 2007: Previsão de tempo do grupo de modelagem atmosférica da UFSM: Implementação e controle de qualidade - Parte II. In: II Encontro Sul Brasileiro de Meteorologia, 2007, Florianópolis. Anais... Florianópolis: CEFET, 2007. 1 CD-ROM.

MELLOR, G. L.; YAMADA, Y. A hierarchy of turbulence closure models for planetary boundary layers. Journal of the Atmospheric Science, v. 31, p. 1791-1806, 1974.

PANETTA, J.; FREITAS, S.; FAZENDA, L. RAMS Regional Atmospheric Modeling System- Version 5.0: Model input namelist parameters. 2nd edição, 2002. 67 p.

PIVA, E. DAL; FEDOROVA, N. Um estudo sobre a formação de nevoeiro de radiação em Porto Alegre. Revista Brasileira de Meteorologia, v. 14, n. 2, p. 47-62, 1999.

SMAGORINSKY, J. General circulation experiments with the primitive equations. Part I: The basic experiment. Monthly Weather Review, v. 91, p. 99-164, 1963.

WALKO, R. L.; BAND, L. E.; BARON, J.; KITTEL, T. G. F.; Lammers, R.; LEE, T. J.; OJIMA, D.; PIELKE, R. A.; 
TAYLOR, C.; TAGUE, C.; TREMBACK, C. J.; VIDALE, P. L. Coupled atmospere-biosphysics-hydrology models for environmental modeling. Journal of Applied Meteorology, v. 39, n.6, p. 931-944, 2000.

WALKO, R. L.; TREMBACK, C. J.; PIELKE, R. A.; COTTON, W. R. An interactive nesting algorithm for stretched grids and variable nesting ratios. Journal of Applied Meteorology, v. 34, p. 994-999, 1995.
WILKS, D. S. Forecast verification. In: . Statistics Methods in the Atmospheric Sciences: An Introduction. San Diego: Academic Press, 1995. p. 253-254. 